\title{
EPATITE DELTA: \\ RICERCA DEL GENOMA VIRALE E \\ CORRELAZIONE CON LA PRESENZA DI ANTICORPI NEL SIERO.
}

\author{
Coppola C., Panza G., Galano G., Romano N., Falco E., \\ Smeraglia R.
}

Servizio di Virologia: Ospedale "C. Ascalesi" ASL NAI.

Direttore: Prof. R. Smeraglia.

Introduzione.

L'epatite Delta interessa il 5\% della popolazione HBsAg positiva. La struttura del virus è quella di un piccolo virus a RNA circolare con una proteina strutturale nota come antigene Delta. L'epatite Delta può essere diagnosticata con marcatori diretti come HDV-RNA con metodica PCR oppure con marcatori indiretti come gli anticorpi anti-Delta. Lo scopo dello studio è stato di valutare i pazienti viremici e non viremici e correlare, in alcuni pazienti, i dati ottenuti con i tests sierologici.

\section{Metodi.}

Sono stati esaminati 103 pazienti, di cui 10 ospedalizzati, e 93 afferenti al nostro ambulatorio. Su tutti è stata determinata la viremia HDV con la Metodica AMPLISENS 255 (NUCLEAR LASER), basata sulla trascrizione inversa (RT), amplificazione con primers specifici e rivelazione su gel di agarosio. In $30 \mathrm{cam}-$ pioni è stata effettuata la determinazione degli anticorpi specifici con metodica immunoenzimatica (NUCLEAR LASER).

\section{Risultati.}

Dei 103 campioni esaminati, 59 (57,3\%) sono risultati positivi, $38(36,9 \%)$ negativi e $6(5,8 \%)$ grey-zone. 30 pazienti sono stati esaminati per gli anticorpi specifici, $16(53,3 \%)$ sono risultati positivi per HDV IgG, 5 (16,7\%) positivi per HDV IgM.

\section{Conclusioni.}

L'estrema sensibilità della reazione permette di individuare la presenza del virus nei pazienti in cui la carica virale è molto bassa e nei pazienti negativi dal punto di vista sierologico. La determinazione dell'HDV-RNA è di grande ausilio nella diagnostica dell'epatite Delta e nel follow-up dei pazienti sottoposti a terapia. 